\section{HUMANAS ESOCIAIS \\ V.8 • N.1 • Abril/Maio/Junho - 2019 \\ ISSN Digital: 2316-3801 \\ ISSN Impresso: 2316-3348 \\ DOI: 10.17564/2316-3801.2019v8n1p39-56}
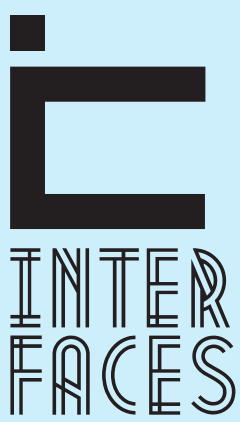

CIENTÍFICAS

\title{
UM ESTUDO DE REVISÃO SISTEMÁTICA DA LITERATURA NACIONAL ENTRE 2007 E 2016 SOBRE OS ADOLESCENTES EM CONFLITO COM A LEI
}

\author{
A STUDY OF SYSTEMATICREVIEW OF NATIONAL LITERATURE \\ BETWEEN २००७ AND २०16 ON ADOLESCENTS IN CONFLLT WTHLAW
}

UN ESTUDIO DE REVIIIIÓN SISTEMÁTICA DE LA LITERATURA NACIONAL ENTRE 2007 Y २०१७ SOBRE LOS ADOLESCENTES EN CONFLICTO CON LA LEY

Liliana de Paiva Bastos ${ }^{1}$ Maria de Lourdes Mattos Barreto ${ }^{2}$

\section{RESUMO}

As crianças e os adolescentes têm sido foco de políticas públicas e discussões em diversas áreas, principalmente no que se refere a sua proteção. Esses sujeitos receberam atenção e tratamentos diferentes no decorrer da história da sociedade brasileira, pois diversas leis e projetos foram formulados. Dentre elas destaca-se o Estatuto da Criança e do Adolescente (ECA), Lei no 8.069 de 1990, que reconhece as crianças e adolescentes como cidadãos de direitos e com prioridades absolutas. Para a coleta dos dados foi realizada a busca pelas teses e dissertações, foram realizadas a partir de um levantamento bibliográfico na base de dados da Biblioteca Digital Brasileira de Teses e Dissertações (BDTD). Foram identificadas dezenove dissertações de mestrado entre 2007 e 2016, havendo uma variação nos anos de publicação das dissertações. Em relação a quantidade de dissertações produzidas por instituição, destacou-se as Universidades Particulares e Estadual. A abordagem mais utilizada pelos pesquisadores, foi a qualitativa, sendo a técnica de pesquisa mais utilizada a entrevista. Já os autores mais referenciados nas publicações foram normas e diretrizes dispostas nas Leis Federais e Decretos Brasileiros. Por fim, entende-se, que questões relacionadas aos adolescentes em conflito com a lei representa importante temática para estudos e pesquisas. Assim, sugerimos a realização de mais pesquisas, em diferentes contextos socioculturais, com o intuito de compreender a vida desses adolescentes e de suas famílias. 


\section{PALAVRAS-CHAVE}

Adolescentes em Conflito com a Lei. Estatuto da Criança e Adolescente. Crianças e Adolescentes. Medidas Socioeducativas. Família de Adolescentes em Conflito com a Lei.

\section{ABSTRACT}

Children and adolescents have been the focus of public policies and discussions in several areas, especially as it relates to their protection. These subjects received different attention and treatment throughout the history of Brazilian society, since several laws and projects were formulated. These include the Statute of the Child and Adolescent (ECA), Law No. 8.069 of 1990, which recognizes children and adolescents as citizens of rights and with absolute priorities. For the data collection, the search for the theses and dissertations was carried out from a bibliographic survey in the database of the Brazilian Digital Library of Theses and Dissertations (BDTD). Nineteen master's dissertations were identified between 2007 and 2016, with a variation in the years of publication of dissertations. In relation to the number of dissertations produced by institution, we highlight the Private and State Universities. The most used approach by the researchers was the qualitative one, being the research technique most used the interview. The authors most referenced in the publications were norms and guidelines set forth in Brazilian Federal Laws and Decrees. Finally, it is understood that issues related to adolescents in conflict with the law represent an important topic for studies and research. Thus, we suggest conducting more research, in different sociocultural contexts, in order to understand the lives of these adolescents and their families.

\section{KEYWORDS}

Adolescents in Conflict with the Law. Statute of the Child and Adolescent. Children and adolescents. Educational measures. Family of Adolescents in Conflict with the Law.

\section{RESUMEN}

Los niños y los adolescentes han sido foco de políticas públicas y discusiones en diversas áreas, principalmente en lo que se refiere a su protección. Estos sujetos recibieron atención y tratamientos diferentes en el transcurso de la historia de la sociedad brasileña, pues diversas leyes y proyectos fueron formulados. Entre ellas se destaca el Estatuto del Niño y del Adolescente (ECA), Ley nº 8.069 
de 1990, que reconoce a los niños y adolescentes como ciudadanos de derechos y con prioridades absolutas. Para la recolección de los datos se realizó la búsqueda de tesis y disertaciones, a partir de un levantamiento bibliográfico en la base de datos de la Biblioteca Digital Brasileña de Tesis y Disertaciones (BDTD). Se identificaron diecinueve disertaciones de maestría entre 2007 y 2016, habiendo una variación en los años de publicación de las disertaciones. Acerca de la cantidad de disertaciones producidas por institución, se destacó las Universidades Particulares y Estadual. El enfoque más utilizado por los investigadores fue la cualitativa, siendo la entrevista la técnica de investigación más utilizada. Los autores más referenciados en las publicaciones fueron normas y directrices dispuestas en las Leyes Federales y Decretos Brasileños. Por último, se entiende que cuestiones relacionadas con los adolescentes en conflicto con la ley representa una importante temática para estudios e investigaciones. Así, sugerimos la realización de más investigaciones, en diferentes contextos socioculturales, con el intuito de comprender la vida de esos adolescentes y de sus familias.

\section{PALABRAS CLAVE}

Adolescentes en Conflicto con la Ley. Estatuto del Niño y Adolescente. Niños y adolescentes. Medidas Sociales. Familia de Adolescentes en Conflicto con la Ley.

\section{INTRODUÇ̄̃̃O}

As crianças e os adolescentes têm sido foco de políticas públicas e discussões em diversas áreas, principalmente no que se refere a sua proteção. Esses sujeitos receberam atenção e tratamentos diferentes no decorrer da história da sociedade brasileira, pois conforme Rizzini e Pilotti (2011), diversas leis e projetos foram formulados com o objetivo de atender as crianças e adolescentes.

A adolescência é um período marcado por diversas mudanças físicas, sociais e cognitivas, no entanto, mais que um período de transição, essa é entendida como uma fase decisiva do ciclo vital, na qual a formação e experiência adquiridas neste período serão importantes e definitivas para todo o ciclo posterior (BRANCALHÃO, 2003). Erik Erikson (1971), afirma que a adolescência é um momento muito importante para a formação da identidade do sujeito.

Essas transformações, associados aos riscos da sociedade contemporânea, como violência, criminalidade, o uso abusivo de drogas lícitas ou não, enfim, uma gama de novos e desafiadores perigos tem levado a exposição das crianças e adolescentes às situações de risco e violação de direitos em que se vive (BRANCALHÃO, 2003).

Assim, o adolescente, mais que qualquer outro ser, está sensível a essas transformações sociais, bem como a cometer atos infracionais. Desse modo, a Constituição Federal de 1988, traz em seu artigo 227, que é dever da família, da sociedade e do Estado assegurar à criança, ao adolescente e ao jovem, com absoluta prioridade, o direito à vida, à saúde, à alimentação, à educação, ao lazer, à 
profissionalização, à cultura, à dignidade, ao respeito, à liberdade e à convivência familiar e comunitária, além de colocá-los a salvo de toda forma de negligência, discriminação, exploração, violência, crueldade e opressão (BRASIL, 1988).

Em conformidade, o Estatuto da Criança e do Adolescente (ECA), Lei nº 8.069 de 1990, afirma esse direito e reconhece as crianças e adolescentes como cidadãos de direitos e com prioridades absolutas. 0 ECA determina medidas socioeducativas aos adolescentes autores de atos infracionais, conforme artigo 112, além de ser uma resposta prática com uma característica educativa e não punitiva. $\mathrm{O}$ ato infracional é a conduta do adolescente que pode ser entendida como crime ou contravenção penal.

Devido a esta realidade surgiu o interesse em fazer uma revisão bibliográfica sistêmica das teses e dissertações que estudam o tema adolescente em conflito com a lei. É importante destacar que a intenção não é esgotar o tema, mas sim apresentar uma análise dos trabalhos de pós-graduação publicadas no período de 2007 a 2016. A análise descreveu o ano de publicação, instituição de ensino, metodologia do estudo, técnicas de pesquisa mais utilizadas e autores mais citados.

\section{METODOLOGIA}

Para atender aos objetivos propostos foi realizada uma pesquisa sistemática. Pode-se dizer que o trabalho de revisão bibliográfica sistemática vai mais além do que utilizar fonte de dados de literatura sobre determinado tema, pois exige um rigor metodológico, utilizando estratégias científicas para limitar e selecionar os artigos, avaliando-os de uma forma que sintetize todas as pesquisas, apontando os pontos mais relevantes e específicos (BOTELHO; CUNHA; MACEDO, 2011).

Para melhor entender a revisão bibliográfica sistêmica Rother (2007), explica que ela é subdividida em quatro outros métodos, que são: meta-analise, revisão sistemática, revisão qualitativa e revisão integrativa. A meta-análise é a soma de vários estudos primários, empregando fórmulas estatísticas que proporcionará um melhor resultado de determinada área de pesquisa (PEREIRA, 2004).

O caminho percorrido para tal revisão, apesar de complexo, possibilitou a síntese e revisão crítica do referencial de base escolhido. As buscas pelas teses e dissertações foram realizadas a partir de um levantamento bibliográfico na base de dados da Biblioteca Digital Brasileira de Teses e Dissertações (BDTD). A BDTD é um portal de busca, que tem por objetivo agrupar as teses e dissertações defendidas em todo o País e por brasileiros no exterior (BDTD/IBICT, 2017).

Para este estudo, a utilização deste sistema de publicação eletrônico, foi escolhido por ser um sistema de dados que reúne todas as teses e dissertações defendidas no Brasil, o que facilitou o acesso aos materiais referentes aos adolescentes em conflito com a lei e suas famílias.

Os descritores utilizados para as pesquisas foram na base de dados foram: "adolescente em conflito com a lei"; "medidas socioeducativas"; e "família de adolescentes em conflito com a lei”. Procedeu-se à leitura dos resumos, sumários e tópicos específicos que apresentassem os objetivos e resultados da pesquisa. 
Para a análise das teses e dissertações encontradas foram utilizados os seguintes critérios de inclusão: (i) teses e dissertações; (ii) publicações desenvolvidas no contexto brasileiro e em linguagem portuguesa; (iii) ter sido publicado entre os anos de 2007 e 2016; (iv) ser do estado de São Paulo; (v) ser da área de conhecimento da psicologia.

\section{RESULTADOS E DISCUSSÕES}

Foram apresentados os resultados do levantamento na base de dados da Biblioteca Digital Brasileira de Teses e Dissertações (BDTD). A partir dos descritores elencados, foram identificadas dezenove dissertações de mestrado entre 2007 e 2016, a partir de critérios de inclusão/exclusão, formando, assim, o corpus de análise deste artigo. Percebeu-se que não houve teses produzidas nesse período de tempo, conforme detalhados a seguir na Tabela 1.

\subsection{DESCRICÃO DOS ESTUDOS}

As análises de dados, referentes aos 19 artigos, foram realizadas a partir das seguintes categorias: 1) Relevância da área de conhecimento; 2) Ano de publicação; 3) Instituição de ensino; 4) Metodologia do estudo; e 5) Autores mais citados. Tais categorias foram elaboradas com vistas a caracterizar e sistematizar os resultados encontrados (TABELA 1).

É importante destacar que área de conhecimento da psicologia, como critério de inclusão de publicações sobre o tema adolescentes em conflito com a lei, se deve ao fato de que o profissional faz parte da equipe multidisciplinar para acompanhamento do adolescente e sua família.

Para o Conselho Federal de Psicologia (2010), a atuação desse profissional junto as medidas socioeducativas é de extrema importância, pois sua atuação contribui para a efetivação das políticas públicas, articulando as açõs entre Estado, família e sociedade. 0 trabalho do psicólogo envolve atendimento ao adolescente e toda a sua família, com o intuito de identificar o problema em seu contexto, levando em consideração as necessidades de cada membro da família, assim como seus valores, crenças e cultura.

Assim, talvez, o interesse do título de mestre em psicologia pelos discentes esteja ligado ao papel que esse profissional exerce com esses sujeitos e suas famílias. De acordo com Fonseca e Develati (2013), a psicologia em sua amplitude tem função importante na atuação nos processos socioeducativos de adolescentes em conflito com a lei para posterior integração social dos mesmos.

Além disso, o Estatuto da Criança e do Adolescente (ECA), regulamentado pela Lei no 8.069 de 1990, implementa medidas socioeducativas que por sua vez são regulamentadas pelo Sistema Nacional de Atendimento Socioeducativo (SINASE), Lei n 12.594 de 2012. 0 atendimento psicológico faz parte das medidas de proteção à criança e ao adolescente, sempre que os direitos reconhecidos no Lei forem ameaçados ou violados, por ação ou omissão da sociedade ou do Estado, por falta, omissão ou abuso dos pais ou responsável e em razão de sua conduta. 
Tabela 1 - Dissertações analisadas

\begin{tabular}{|c|c|c|c|c|}
\hline Ordem & Autor - Ano - IES - Titulação & Título da pesquisa & $\begin{array}{c}\text { Participantes da } \\
\text { pesquisa }\end{array}$ & $\begin{array}{c}\text { Metodologia } \\
\text { do Estudo }\end{array}$ \\
\hline 1 & $\begin{array}{c}\text { Viviane Fernanda dos Santos } \\
\text { - 2007. Universidade Estadual } \\
\text { Paulista (UNESP) } \\
\text { Mestrado em Psicologia. }\end{array}$ & $\begin{array}{l}\text { A lei do desejo ou o } \\
\text { desejo da lei? Pacto } \\
\text { edípico e pacto social } \\
\text { no sentimento de } \\
\text { pertença familiar de } \\
\text { adolescentes em con- } \\
\text { flito com a lei }\end{array}$ & $\begin{array}{l}\text { Três adolescentes } \\
\text { em conflito com } \\
\text { a lei em cumpri- } \\
\text { mento de medida } \\
\text { sócio-educativa } \\
\text { de internação }\end{array}$ & $\begin{array}{l}\text { Entrevistas } \\
\text { semi-estrutu- } \\
\text { radas }\end{array}$ \\
\hline 2 & $\begin{array}{l}\text { Almunita dos Santos F. Pereira } \\
\text { - 2007. Pontifícia Universi- } \\
\text { dade Católica de São Paulo } \\
\text { (PUC). Mestrado em Psicologia } \\
\text { da Educação }\end{array}$ & $\begin{array}{l}\text { A vida em semiliber- } \\
\text { dade um estudo sobre } \\
\text { adolescentes em con- } \\
\quad \text { flito com a lei }\end{array}$ & $\begin{array}{c}3 \text { adolescentes } \\
\text { do sexo masculi- } \\
\text { no entre } 16 \text { e } 17 \\
\text { anos em cumpri- } \\
\text { mento de medida } \\
\text { socioeducativa } \\
\text { de Semiliberdade }\end{array}$ & $\begin{array}{l}\text { Abordagem } \\
\text { qualitativa } \\
\text { - Entrevista } \\
\text { semi-aberta }\end{array}$ \\
\hline 3 & $\begin{array}{l}\text { Camila Miyagui - } 2008 . \\
\text { Pontifícia Universidade Católi- } \\
\text { ca de São Paulo (PUC) Mestra- } \\
\text { do em Psicologia Social }\end{array}$ & $\begin{array}{l}\text { O adolescente e a me- } \\
\text { dida socioeducativa de } \\
\text { prestação de serviços à } \\
\text { comunidade }\end{array}$ & $\begin{array}{c}2 \text { adolescentes } \\
\text { em cumprimento } \\
\text { de medida de } \\
\text { prestação de ser- } \\
\text { viços à comuni- } \\
\text { dade, no interior } \\
\text { do Paraná } \\
\end{array}$ & $\begin{array}{l}\text { Abordagem } \\
\text { qualitativa } \\
\text { Entrevista }\end{array}$ \\
\hline 4 & $\begin{array}{l}\text { Vanessa Mies Bombardi - } \\
\text { 2008. Instituto de Psicologia } \\
\text { da Universidade de São Paulo } \\
\text { (USP) Mestrado em Psicologia }\end{array}$ & $\begin{array}{l}\text { A rebelião do dia-a- } \\
\text {-dia: uma leitura sobre } \\
\text { adolescentes autores } \\
\text { de atos infracionais }\end{array}$ & $\begin{array}{c}4 \text { adolescentes } \\
\text { cumprimento de } \\
\text { medida socioedu- } \\
\text { cativa de ambos } \\
\text { sexos }\end{array}$ & $\begin{array}{l}\text { Estudo de } \\
\text { caso } \\
\text { Análise Docu- } \\
\text { mental } \\
\text { Entrevista } \\
\text { Observação } \\
\text { Direta }\end{array}$ \\
\hline 5 & $\begin{array}{l}\text { José Roberto Oliveira Santos } \\
\text { - 2008. Universidade Estadual } \\
\text { Paulista Faculdade de Ciências } \\
\text { e Letras de Assis (UNESP) } \\
\text { Mestrado em Psicologia }\end{array}$ & $\begin{array}{l}\text { O adolescente em } \\
\text { conflito com a lei na } \\
\text { cidade de Assis-SP }\end{array}$ & $\begin{array}{c}\text { Processos de } \\
\text { adolescentes } \\
\text { encaminhados } \\
\text { para o cumpri- } \\
\text { mento de medida } \\
\text { socioeducativa } \\
\text { de nov. } 2003 \text { a } \\
\text { jun. } 2008\end{array}$ & $\begin{array}{l}\text { Pesquisa } \\
\text { Quantitativa e } \\
\text { Qualitativa } \\
\text { Análise de } \\
\text { Documentos }\end{array}$ \\
\hline
\end{tabular}




\begin{tabular}{|c|c|c|c|c|}
\hline Ordem & Autor - Ano - IES - Titulação & Título da pesquisa & $\begin{array}{c}\text { Participantes da } \\
\text { pesquisa }\end{array}$ & $\begin{array}{l}\text { Metodologia } \\
\text { do Estudo }\end{array}$ \\
\hline 6 & $\begin{array}{l}\text { Clodine Janny Teixeira - } 2009 \\
\text { Instituto de Psicologia da Uni- } \\
\text { versidade de São Paulo (USP). } \\
\text { Mestrado em Psicologia }\end{array}$ & $\begin{array}{l}\text { O fenômeno da morte } \\
\text { na adolescência sob } \\
\text { o olhar de jovens em } \\
\text { conflito com a lei }\end{array}$ & $\begin{array}{l}\text { Cinco adolescen- } \\
\text { tes com idades } \\
\text { entre } 10 \text { e } 19 \\
\text { anos cumprindo } \\
\text { medida socioe- } \\
\text { ducativa em meio } \\
\text { aberto }\end{array}$ & $\begin{array}{l}\text { Pesquisa } \\
\text { Qualitativa } \\
\text { Entrevista } \\
\text { Aberta } \\
\text { Análise de } \\
\text { Conteúdo }\end{array}$ \\
\hline 7 & $\begin{array}{l}\text { Maria Cristina Maruschi - } \\
\text { 2010. Universidade de São } \\
\text { Paulo, Faculdade de Filosofia, } \\
\text { Ciências e Letras de Ribeirão } \\
\text { Preto (USP). Mestrado em } \\
\text { Ciências. Área da Psicologia }\end{array}$ & $\begin{array}{l}\text { Avaliação de ado- } \\
\text { lescente em conflito } \\
\text { com a lei a partir dos } \\
\text { conceitos de risco e } \\
\text { necessidade associa- } \\
\text { dos à persistência da } \\
\text { conduta infracional }\end{array}$ & $\begin{array}{l}\text { Quarenta ado- } \\
\text { lescentes que } \\
\text { praticaram ato } \\
\text { infracional } \\
\text { e seus pais }\end{array}$ & $\begin{array}{l}\text { Entrevistas } \\
\text { semi-estrutu- } \\
\text { radas }\end{array}$ \\
\hline 8 & $\begin{array}{l}\text { Luzia Jusciliane Claro - } 2010 \\
\text { Pontifícia Universidade Católi- } \\
\text { ca de São Paulo (PUC) } \\
\text { Mestrado Psicologia Clínica }\end{array}$ & $\begin{array}{l}\text { Constribuições win- } \\
\text { nicottianas para as } \\
\text { práticas sociais- um } \\
\text { olhar para a liberdade } \\
\text { assistida }\end{array}$ & $\begin{array}{l}\text { Um adolescente } \\
\text { cumprimento de } \\
\text { medida socioedu- } \\
\text { cativa de liberda- } \\
\text { de assistida }\end{array}$ & $\begin{array}{l}\text { Abordagem } \\
\text { Qualitativa } \\
\text { Estudo de } \\
\text { Caso } \\
\text { Pesquisa } \\
\text { Teórica } \\
\text { Entrevista }\end{array}$ \\
\hline 9 & $\begin{array}{c}\text { Valéria Cristina Zane - } 2010 \\
\text { Universidade Estadual Pau- } \\
\text { lista “Júlio de Mesquita Filho" } \\
\text { (UNESP). Mestrado Psicologia } \\
\text { do Desenvolvimento e Apren- } \\
\text { dizagem }\end{array}$ & $\begin{array}{l}\text { Adolescentes em con- } \\
\text { flitos com a lei e suas } \\
\text { famílias }\end{array}$ & $\begin{array}{l}\text { Trinta adolescen- } \\
\text { tes em conflito } \\
\text { com a lei e suas } \\
\text { famílias entre } 15 \\
\text { e } 18 \text { anos do sexo } \\
\text { masculino em } \\
\text { conflito com a lei } \\
\text { e suas mães }\end{array}$ & $\begin{array}{l}\text { Questionários } \\
\text { e Entrevistas }\end{array}$ \\
\hline 10 & $\begin{array}{l}\text { Juliana dos Santos Rodrigues } \\
\text { - 2011. Universidade Metodis- } \\
\text { ta de São Paulo Mestrado em } \\
\text { Psicologia da Saúde }\end{array}$ & $\begin{array}{l}\text { Adolescência e } \\
\text { transtorno de conduta: } \\
\text { estudo do funciona- } \\
\text { mento psíquico e da } \\
\text { percepção da figura } \\
\text { paterna de adolescen- } \\
\text { tes infratores }\end{array}$ & $\begin{array}{c}\text { Seis casos de } \\
\text { adolescentes em } \\
\text { cumprimento de } \\
\text { medida socioedu- } \\
\text { cativa }\end{array}$ & $\begin{array}{l}\text { Procedimento } \\
\text { de Desenho- } \\
\text {-Estória com } \\
\text { Tema } \\
\text { Entrevistas } \\
\text { semi-estrutu- } \\
\text { radas }\end{array}$ \\
\hline
\end{tabular}




\begin{tabular}{|c|c|c|c|c|}
\hline Ordem & Autor - Ano - IES - Titulação & Título da pesquisa & $\begin{array}{c}\text { Participantes da } \\
\text { pesquisa }\end{array}$ & $\begin{array}{c}\text { Metodologia } \\
\text { do Estudo }\end{array}$ \\
\hline 11 & $\begin{array}{c}\text { Viviane Terres Ribeiro - } 2012 \\
\text { Universidade Estadual Paulista } \\
\text { (UNESP) Mestrado em Psico- } \\
\text { logia }\end{array}$ & $\begin{array}{c}\text { O adolescente em } \\
\text { liberdade assistida, } \\
\text { genitores e avós: } \\
\text { vinculação e práticas } \\
\text { parentais }\end{array}$ & $\begin{array}{c}\text { Dez adolescente } \\
\text { em conflito com } \\
\text { a lei inseridos no } \\
\text { programa CREAS } \\
\text { e seus familiares } \\
\text { de mais duas } \\
\text { gerações }\end{array}$ & $\begin{array}{l}\text { Abordagem } \\
\text { qualitativa } \\
\text { Entrevista }\end{array}$ \\
\hline 12 & $\begin{array}{l}\text { Vânia Aparecida Calado - } \\
2010 \text { - Instituto de Psicologia } \\
\text { da Universidade de São Paulo } \\
\text { (USP). Mestrado em Psicologia }\end{array}$ & $\begin{array}{l}\text { Escolarização, gênero } \\
\text { e conflito com a lei: } \\
\text { um estudo de registros } \\
\text { de atendimento a ado- } \\
\text { lescentes em medida } \\
\text { socioeducativa }\end{array}$ & $\begin{array}{l}\text { Adolescentes en- } \\
\text { tre } 12 \text { e } 18 \text { anos } \\
\text { em cumprimento } \\
\text { de medida de } \\
\text { ambos o sexos }\end{array}$ & $\begin{array}{c}\text { Qualitativa } \\
\text { Estudo de } \\
\text { caso } \\
\text { Análise Docu- } \\
\text { mental } \\
\text { Entrevistas } \\
\text { Análise Quan- } \\
\text { titativa }\end{array}$ \\
\hline 13 & $\begin{array}{l}\text { Beatriz Borges Brambilla - } \\
\text { 2012. Universidade Metodista } \\
\text { de São Paulo. Mestrado em } \\
\text { Psicologia da Saúde }\end{array}$ & $\begin{array}{c}\text { Percepção de suporte } \\
\text { familiar de adolescen- } \\
\text { tes em conflito com } \\
\text { a lei }\end{array}$ & $\begin{array}{c}5 \text { adolescentes } \\
\text { em cumprimento } \\
\text { de medida socio- } \\
\text { educativa }\end{array}$ & $\begin{array}{c}\text { Estudo Descri- } \\
\text { tivo } \\
\text { Inventário de } \\
\text { Percepção de } \\
\text { Suporte Fa- } \\
\text { miliar (IPSF). } \\
\text { Entrevista } \\
\text { semi dirigida } \\
\text { individual }\end{array}$ \\
\hline 14 & $\begin{array}{l}\text { Rodrigues Gomes - } 2013 \\
\text { Pontifícia Universidade Católi- } \\
\text { ca de São Paulo (PUC) } \\
\text { Mestrado em Psicologia Social }\end{array}$ & $\begin{array}{l}\text { Práticas de socioedu- } \\
\text { cação à luz da Justiça } \\
\text { Restaurativa: potencia- } \\
\text { lização de mudanças? }\end{array}$ & $\begin{array}{l}\text { Funcionários e } \\
\text { jovens dos cen- } \\
\text { tros de atendi- } \\
\text { mento }\end{array}$ & $\begin{array}{c}\text { Círculos de } \\
\text { Paz } \\
\text { Círculo } \\
\text { Construção de } \\
\text { Senso Comu- } \\
\text { nitário }\end{array}$ \\
\hline
\end{tabular}




\begin{tabular}{|c|c|c|c|c|}
\hline Ordem & Autor - Ano - IES - Titulação & Título da pesquisa & $\begin{array}{l}\text { Participantes da } \\
\text { pesquisa }\end{array}$ & $\begin{array}{l}\text { Metodologia } \\
\text { do Estudo }\end{array}$ \\
\hline 15 & $\begin{array}{l}\text { Jorge Luiz da Silva - } 2013 \\
\text { Universidade de São Paulo } \\
\text { - (USP). Mestre em Ciências } \\
\text { Área de conhecimento da } \\
\text { Psicologia }\end{array}$ & $\begin{array}{l}\text { A regulação da con- } \\
\text { duta delituosa pela } \\
\text { escola: um estudo } \\
\text { comparativo entre } \\
\text { adolescentes judicia- } \\
\text { rizados e não-judicia- } \\
\text { rizados no contexto } \\
\text { brasileiro }\end{array}$ & $\begin{array}{c}60 \text { adolescentes } \\
\text { (60 em conflito } \\
\text { com a lei e } 30 \\
\text { não infratores) } \\
\text { entre } 14 \text { e } 18 \\
\text { anos incompletos }\end{array}$ & $\begin{array}{c}\text { Entrevista } \\
\text { Escala Escola } \\
\text { do Inventário } \\
\text { MASPAQ } \\
\text { Questionário } \\
\text { Socioeconô- } \\
\text { mico }\end{array}$ \\
\hline 16 & $\begin{array}{l}\text { Luciana Ferreira Silva -2014 } \\
\text { Pontifícia Universidade Católi- } \\
\text { ca de São Paulo (PUC) } \\
\text { Mestrado em Psicologia Social }\end{array}$ & $\begin{array}{l}\text { Crime, Ostentação e } \\
\text { Afetividade: um estudo } \\
\text { psicossocial sobre o } \\
\text { adolescente em confli- } \\
\text { to com a Lei }\end{array}$ & $\begin{array}{l}\text { Cinco adolescen- } \\
\text { tes em cumpri- } \\
\text { mento de medida } \\
\text { socioeducativa } \\
\text { em meio-aberto } \\
\text { entre } 12 \text { e } 21 \text { de } \\
\text { ambos sexos }\end{array}$ & $\begin{array}{c}\text { Pesquisa Qua- } \\
\text { litativa } \\
\text { Entrevistas } \\
\text { História de } \\
\text { Vida Grupo } \\
\text { Focal }\end{array}$ \\
\hline 17 & $\begin{array}{l}\text { João Victor de Souza Reis - } \\
\text { 2014. Instituto de Psicologia } \\
\text { da Universidade de São Paulo } \\
\text { (USP) Mestrado em Psicologia }\end{array}$ & $\begin{array}{l}\text { Onde está o pai? O } \\
\text { lugar do homem em } \\
\text { famílias “matrifocais” } \\
\text { pobres na cidade de } \\
\text { São Paulo } \\
\end{array}$ & $\begin{array}{l}\text { Familiares dos } \\
\text { adolescentes } \\
\text { sexo masculino }\end{array}$ & Campo tema \\
\hline 18 & $\begin{array}{l}\text { Fabio Meirelles Alves - } 2016 \\
\text { Universidade de São Paulo - } \\
\text { (USP). Mestre em Ciências } \\
\text { Área de conhecimento da } \\
\text { Psicologia }\end{array}$ & $\begin{array}{c}\text { O comportamento } \\
\text { social na adolescência: } \\
\text { as normas e a rotina na } \\
\text { regulação da conduta } \\
\text { delituosa }\end{array}$ & $\begin{array}{c}150 \text { adolescentes } \\
\text { (48 em conflito } \\
\text { com a lei e } 102 \\
\text { não infratores) } \\
\text { entre } 12 \text { e } 18 \\
\text { anos incompletos } \\
\text { do sexo mascu- } \\
\text { lino }\end{array}$ & $\begin{array}{c}\text { Abordagem } \\
\text { Quanti/Quali } \\
\text { Questionário } \\
\text { Entrevista } \\
\text { Questionário } \\
\text { de Normas do } \\
\text { MASPAQ }\end{array}$ \\
\hline 19 & $\begin{array}{l}\text { Maria Mercedes Whitaker } \\
\text { Kehl Vieira Bicudo Guarnieri - } \\
\text { 2016. Pontifícia Universidade } \\
\text { Católica de São Paulo (PUC) } \\
\text { Mestrado em Psicologia Social }\end{array}$ & $\begin{array}{l}\text { O trabalho das psicó- } \\
\text { logas na fundação: } \\
\text { trajetórias e desafios }\end{array}$ & $\begin{array}{l}\text { Psicólogas da } \\
\text { Fundação Casa }\end{array}$ & $\begin{array}{c}\text { Pesquisa Qua- } \\
\text { litativa } \\
\text { Entrevista } \\
\text { Observação } \\
\text { Participante }\end{array}$ \\
\hline
\end{tabular}

Fonte: Dados da pesquisa (2017).

De acordo com os critérios de inclusão, as 19 dissertações são referentes aos últimos 10 anos. Percebeu-se que não houve publicações no ano de 2015. Nos demais anos, houve variação, sendo 
que ao menos um artigo foi publicado. 0 ano com maior número de publicações foi 2004, com 4 produções; seguido do ano 2008, com 3 produções; e dos anos 2007, 2012, 2013, 2014 e 2016, com duas produções em cada ano, conforme a Figura 1.

Figura 1 - Ano de publicação

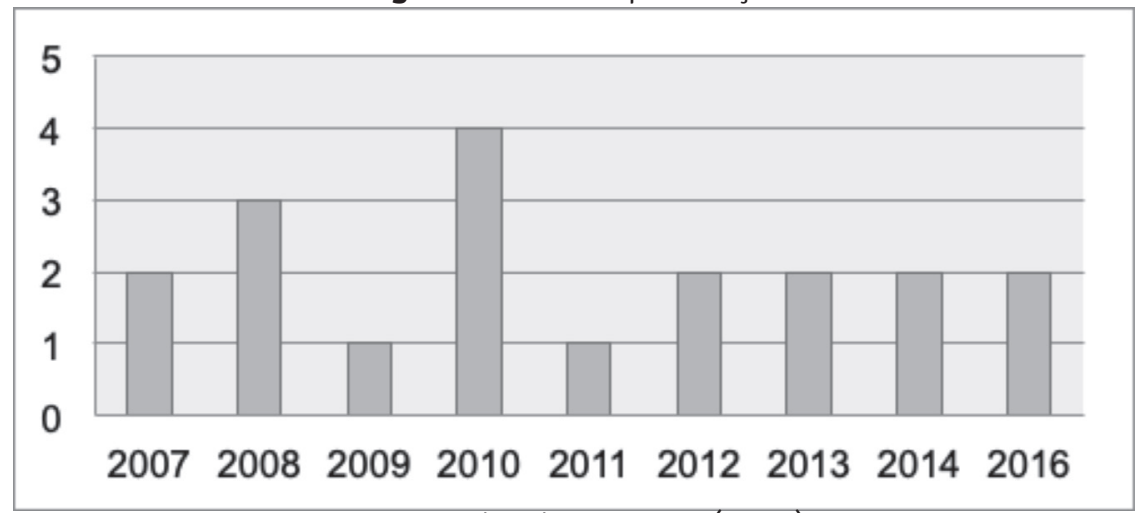

Fonte: Dados da pesquisa (2017).

No entanto, não foi possível identificar uma justificativa para o fato de não haver pesquisas publicadas, no ano de 2015, na modalidade de pós-graduação (mestrado e doutorado). Apesar disso, percebeu-se que a maioria, ou seja, quase $70 \%$ das dissertações foram produzidas a partir do ano de 2010, talvez um dado importante para explicar o aumento de pesquisas nessa data pode estar relacionado ao fato de que no ano de 2006 foi encaminhado ao Congresso Nacional um documento com propostas para suprir lacunas que ficaram em aberto no ECA (Lei 8.069/90). Além disso, também foi aprovado a resolução no 119 do Conselho Nacional dos Direitos da Criança e do Adolescente (CONANDA), que estabeleceu o Sistema Nacional de Atendimento Socioeducativo (SINASE) e no ano de 2009 houve a Tipificação Nacional dos Serviços Socioassistenciais, resolução n 109 , referente aos serviços prestados nas redes de atendimento de Proteção Social Básica e de Proteção Social Especial de Média e Alta Complexidade (TRESOLDI, 2015).

O Mapa da Violência (2016), mostra que é nas grandes metrópoles que se concentram o maior índice de violência, o que pode ser um indicador que despertou o interesse de pesquisas sobre violência entre os adolescentes no Estado de São Paulo (WAISELFISZ, 2016).

Além disso, o Levantamento Anual SINASE 2014, publicado em 2017, pelo Ministério dos Direitos Humanos, por meio da Secretaria Nacional dos Direitos da Criança e do Adolescente, mostra o registro anual para 2014 de atos infracionais registrados no país, observando-se a distribuição por Região e por Unidade da Federação (UF). Na região do Sudeste, o Estado de São Paulo foi o que mais registrou atos infracionais, com 10211 registros, seguido de Minas Gerais com 1853 registros; Rio de Janeiro com 1655 registros; e Espírito Santo com 991 registros.

Por meio da análise destas dissertações foi possível identificar a abordagem metodológica adota- 
da pelas pesquisas, os tipos de pesquisa, os procedimentos de coleta e análise dos dados e os autores mais citados na metodologia dos estudos.

Estudos de caráter qualitativo foram predominantes entre as dissertações, ou seja, dezesseis (84\%) pesquisas utilizaram a abordagem qualitativa, ao contrário da abordagem quantitativa em que não foram realizadas pesquisas, utilizando somente esta técnica. Os demais estudos, três (16\%), conciliaram as técnicas qualitativa e quantitativa de coleta e análise de dados, conforme a figura 2.

Figura 2 - Metodologias utilizadas nos estudos

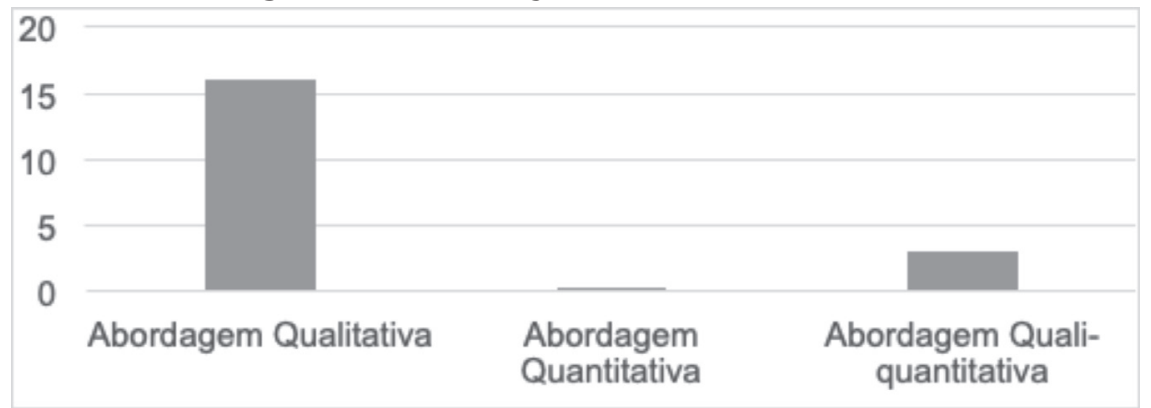

Fonte: Dados da pesquisa (2017).

Conforme mostra a Fgura 3, na abordagem qualitativa, a autora mais citada foi Minayo, sendo que dez (53\%), das dissertações em análise citaram a mesma. Logo, os autores Bardin e Lüdke; André apareceram nas dissertações com três (32\%) citações cada, seguido dos demais autores que representam três (15\%) citações no total.

Figura 3 - Autores mais citados na metodologia dos estudos

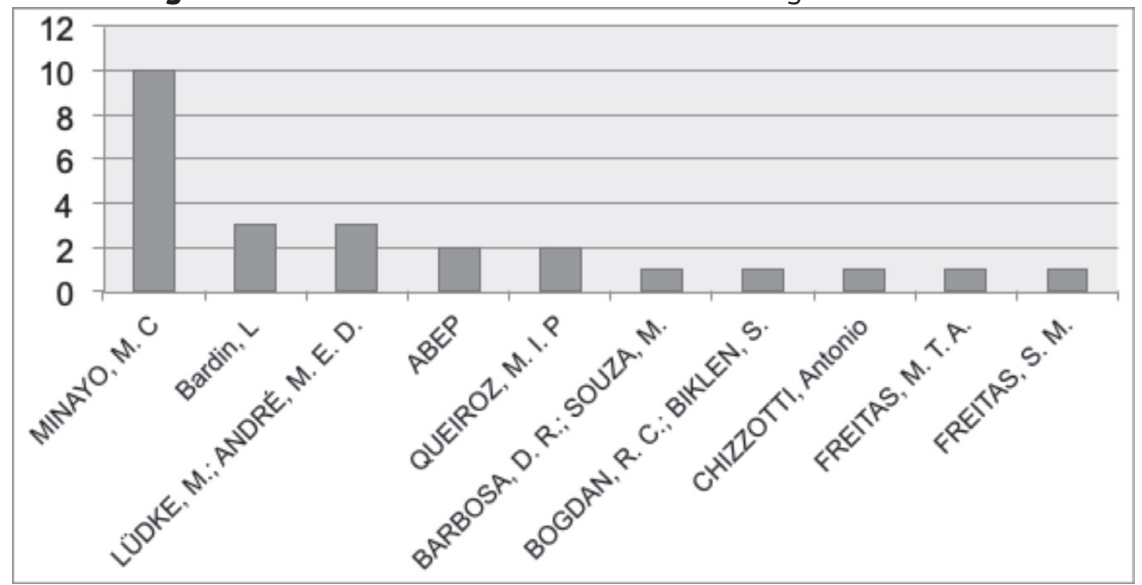

Fonte: Dados da Pesquisa (2017). 
Entendemos que, tratando de um tema complexo, a escolha da abordagem qualitativa pelos autores foi utilizada como a mais adequada para tratar a temática adolescentes em conflito com a lei, uma vez que a mesma permite abranger a complexidade do assunto ao utilizar simultaneamente diferentes técnicas de pesquisa, possibilitando assim abranger o contexto como um todo, além da percepção e análise das dimensões, significados e subjetividade dos envolvidos.

Sobre isso, Ludke e André (2013) afirmam que,

Os dados coletados são predominantemente descritivos. 0 material coletado nestas pesquisas é rico em descrições de pessoas, situações, acontecimentos; inclui transições de entrevistas e depoimentos, fotografias, desenhos e estrato de vários tipos de documentos [...] todos os dados da realidade são considerados importantes. (LUDKE; ANDRÉ, 2003 apud PEREIRA, 2007, p. 40).

Talvez seja por isso que a temática: adolescentes em conflito com a lei, requer a abordagem qualitativa, pois ela permite levantar dados, bem como compreender as motivações, comportamentos, sentimentos, percepções e expectativas desse grupo.

Em relação aos procedimentos, conforme demonstrado na Figura 4, as dissertações apresentaram uma grande variação na escolha das técnicas de coleta de dados. Entre as diversas técnicas de coleta de dados, a entrevista se destacou nos estudos, sendo que apareceu em dezesseis (85\%) pesquisas, seja como único procedimento de coleta de dados, ou em conjunto com outras técnicas.

A entrevista se destaca por se tratar de importante técnica de pesquisa qualitativa. Nos estudos analisados, identificou-se diferentes tipos de entrevista, sendo elas estruturada, semiestruturada ou aberta, no entanto todas tinham o mesmo objetivo, o de permitir aos participantes abordar livremente o tema proposto.

Figura 4 - Procedimentos de coleta e análise dos dados utilizado nas dissertações

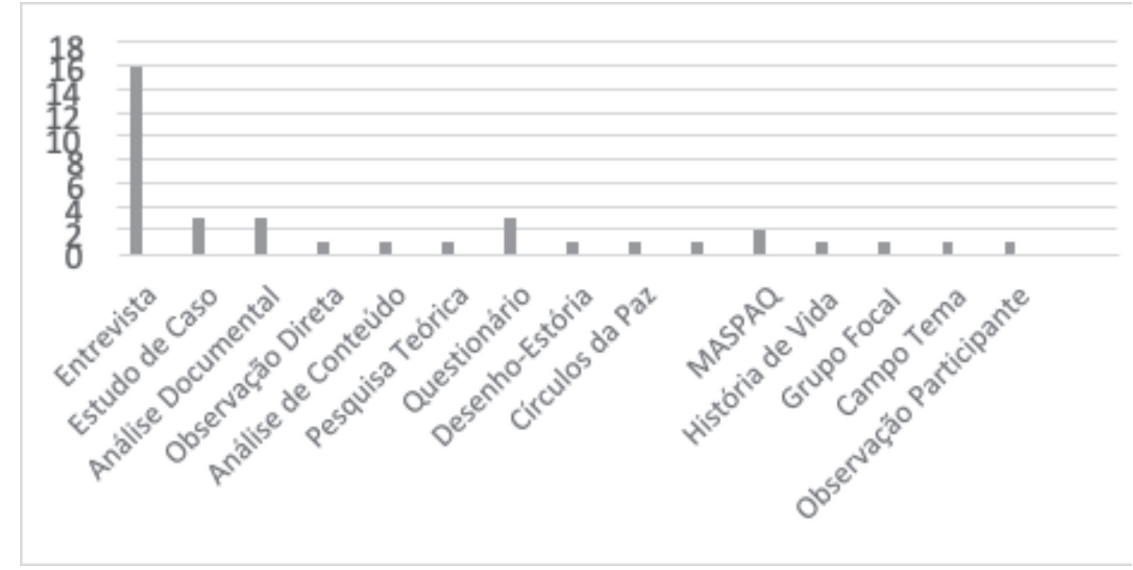

Fonte: Dados da Pesquisa (2017). 


\section{CONSIDERAÇÕES FINAIS}

Por meio da análise destas dissertações, esta pesquisa contribuiu para identificar o ano de publicação, a instituição de ensino, a abordagem metodológica adotada pelas pesquisas, autores mais citados na metodologia, a área de conhecimento, os objetivos e principais resultados das dissertações analisadas.

Os resultados revelam que houve uma variação nos anos de publicação das dissertações, sendo que 2015 não houve publicações e 2004 foi o ano com o maior número de publicações. Em relação a quantidade de dissertações produzidas por instituição, as que mais aparecerem foram Universidades Particulares e Estadual.

A abordagem mais utilizada pelos pesquisadores, foi a qualitativa, o que não exclui a abordagem quantitativa, uma vez que elas se complementam e foram conciliadas por alguns pesquisadores. Entre as diversas técnicas de coleta de dados, a entrevista se destacou nos estudos, o que sugere ser considerada a técnica mais adequada para esse tipo de estudo em que é relevante considerar a opinião dos participantes.

Entende-se, que questões relacionadas aos adolescentes em conflito com a lei representa importante temática para estudos e pesquisas. Assim, sugere-se a realização de mais pesquisas, com os egressos das medidas socioeducativas com o intuito de verificar se as medidas estão tento resultados para o rompimento com a prática infracional na vida desses adolescentes. Torna-se essencial para uma visão mais ampla a respeito do fenômeno em questão.

\section{REFERÊNCIAS}

ALVES, Fabio Meirelles. $\mathbf{O}$ comportamento social na adolescência: as normas e a rotina na regulação da conduta delituosa; 2016. 155f. Dissertação (Mestrado em Ciências), Universidade de São Paulo, Ribeirão Preto, 2016.

BOMBARDI, Vanessa Mies. A rebelião do dia-a-dia: uma leitura sobre adolescentes autores de atos infracionais. 2008. 342f. Dissertação (Mestrado em Psicologia Social) - Instituto de Psicologia da Universidade de São Paulo, São Paulo, 2008.

BOTELHO, Louise Lira Roedel; CUNHA, Cristiano Castro de Almeida; MACEDO, Marcelo. 0 método da revisão integrativa nos estudos organizacionais. Belo Horizonte: Gestão e Sociedade, v. 5, n. 11, p. 121-136, 2011.

BRAMBILLA, Beatriz Borges. Percepção de suporte familiar de adolescente em conflito com a lei. 2012. 95f. Dissertação (Mestrado em Psicologia da Saúde), Faculdade de Saúde da Universidade Metodista de São Paulo, São Bernardo do Campo, 2012. 
BRANCALHÃO, Walkíria Rodrigues Duarte. A educação para o adolescente em conflito com a lei: mecanismo de inserção ou de exclusão social? 2003. 130f. Dissertação (Mestrado em Educação) - Faculdade de Filosofia e Ciências da Universidade Estadual Paulista "Julio Mesquita Filho", Marília, 2003.

BRASIL. Constituição Federal da República. Constituição da República Federativa do Brasil: promulgada em 5 de outubro de 1988. Brasília: Governo Federal, 1988.

BRASIL. Estatuto da Criança e Adolescente. Lei n 8.069 de 13 de julho de 1990. Dispõe sobre o Estatuto da Criança e do Adolescente e dá outras providências. Brasília, DF, 1990.

BRASIL. Levantamento Anual SINASE 2014. Brasília: Secretaria Nacional dos Direitos da Criança e do Adolescente do Ministério dos Direitos Humanos. Brasília-DF: CONANDA, 2017.

CALADO, Vânia Aparecida. Escolarização, gênero e conflito com a lei: um estudo de registros de atendimento a adolescentes em medida socioeducativa. 2010, 223f. Dissertação (Mestrado em Psicologia) - Instituto de Psicologia da Universidade de São Paulo, São Paulo, 2010.

CLARO, Luzia Jusciliane. Contribuições winnicottianas para as práticas sociais - um olhar para a liberdade assistida, 2010. 158f. Dissertação (Mestrado em Psicologia Clínica) - Pontifícia Universidade Católica de São Paulo, São Paulo, 2010.

CONSELHO FEDERAL DE PSICOLOGIA. Referências técnicas para atuação de psicólogos no âmbito das medidas socioeducativas em Unidades de internação. Brasília: CFP, 2010.

ERIKSON, Erik. Infância e sociedade. Tradulçao de Gildásio Amado. Rio de Janeiro: Zahar Editores, 1971.

\section{GOMES, Geisa Rodrigues. Práticas de socioeducação à luz da Justiça Restaurativa:} potencialização de mudanças? 2013. 137f. Dissertação (Mestrado em Psicologia Social) - Pontifícia Universidade Católica de São Paulo, São Paulo, 2013.

GUARNIERI, Maria Mercedes Whitaker Kehl Vieira Bicudo. 0 trabalho das psicólogas na Fundação Casa: trajetórias e desafios. 2016. 219f. Dissertação (Mestrado em Psicologia Social) - Pontifícia Universidade Católica de São Paulo, São Paulo, 2016.

MARUSCHI, Maria Cristina. Avaliação de adolescentes em conflito com a lei a partir dos conceitos de risco e necessidade associados à persistência da conduta infracional. 2010. 123f. Dissertação (Mestrado em Ciências) - Universidade de São Paulo, Ribeirão Preto, 2010. 


\section{MIYAGUI, Camila. $\mathbf{0}$ adolescente e a medida socioeducativa de prestação de serviços à}

comunidade. 2008. 214f. Dissertação (Mestrado em Psicologia Social) - Pontifícia Universidade Católica de São Paulo, São Paulo, 2008.

PEREIRA, Almunita dos Santos F. A vida em semiliberdade: um estudo sobre adolescentes em conflito com a lei. 2007. 111f. Dissertação (Mestrado em Psicologia da Educação) - Pontifícia Universidade Católica de São Paulo, São Paulo, 2007.

PEREIRA, R.C.F. Explorando as possibilidades da meta-análise em marketing. In: Encontro da Associação Nacional dos programas de pós-graduação em administração, 28, 2004, Curitiba. Anais... Curitiba: Enanpad, 2004.

REIS, João Victor de Souza. Onde está o pai? O lugar do homem em famílias "matrifocais" pobres na cidade de São Paulo. 2014. 109f. Dissertação (Mestrado em Psicologia) - Universidade de São Paulo, São Paulo, 2014.

RIBEIRO, Viviane Terres. 0 adolescente em liberdade assistida, genitores e avós: vinculação e práticas parentais. 2012. 137f. Dissertação (Mestrado em Psicologia) - Universidade Estadual Paulista, Faculdade de Ciências, Bauru, 2012.

RODRIGUES, Juliana dos Santos. Adolescência e transtorno de conduta: estudo do funcionamento psíquico e da percepção da figura paterna de adolescente infratores. 2011. 110f. Dissertação (Mestrado em Psicologia da Saúde) - Faculdade de Saúde da Universidade Metodista de São Paulo, São Bernardo do Campo, 2011.

ROTHER, E. T. Revisão sistemática x revisão narrativa. Acta Paulista de Enfermagem, São Paulo, v. 20, n. 2, p. 5-6, 2007.

SANTOS, José Roberto Oliveira. $\mathbf{O}$ adolescente em conflito com a lei na cidade de Assi-SP. 2008. 108f. Dissertação (Mestrado em Psicologia) - Universidade Estadual Paulista, Assis, 2008.

SANTOS, Viviane Fernanda dos. A Lei do desejo ou o desejo da Lei? Pacto edípico e pacto social no sentimento de pertença familiar de adolescentes em conflito com a lei. 2007. 156f. Dissertação (Mestrado em Psicologia) - Universidade Estadual Paulista, Faculdade de Ciências e Letras de Assis, Assis, 2007.

SILVA, Jorge Luiz da. A regulação da conduta delituosa pela escola: um estudo comparativo entre adolescentes judiciarizados e não-judiarizados no contexto brasileiro. 2013. 130f. Dissertação (Mestrado em Ciências) - Faculdade de Filosofia, Ciências e Letras de Ribeirão Preto da Universidade de São Paulo, Ribeirão Preto, 2013. 
SILVA, Luciana Ferreira. Crime, ostentação e afetividade: um estudo psicossocial sobre o adolescente em conflito com a lei. 2014. 129f. Dissertação (Mestrado em Psicologia Social) Pontifícia Universidade Católica de São Paulo, São Paulo, 2014.

TEIXEIRA, Clodine Janny. 0 fenômeno da morte na adolescência sob o olhar de jovens em conflito com a lei. 2009. 185 f. Dissertação (Mestrado em Psicologia), Instituto de Psicologia da Universidade de São Paulo, São Paulo, 2009.

TRESOLDI, Mara Eloisa. Caleidoscópio: Desvelando o Adolescente em conflito com a lei. 2015. $153 f$. Tese (Doutorado em Educação) - Universidade Federal do Rio Grande do Sul, Porto Alegre, 2015.

WAISELFISZ, Julio Jacobo. Mapa da violência 2016: homicídios por armas de fogo no Brasil. Brasil: FLACSO, 2016.

ZANE, Valéria Cristina. Adolescentes em conflito com a lei e suas famílias. 2010. 203f. Dissertação (Mestrado em Psicologia do Desenvolvimento e Aprendizagem) - Universidade Estadual Paulista “Júlio de Mesquita Filho", Bauru, 2010. 


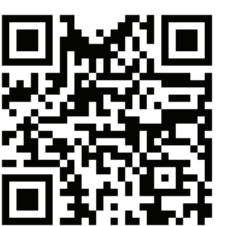

A autenticidade desse artigo pode ser conferida no site https://periodicos. set.edu.br
1 Psicóloga formada pela Faculdade de Ciências Biológicas e da Saúde - Univiçosa; Mestranda do Programa de Pós-Graduação em Economia Doméstica da Universidade Federal de Viçosa. E-mail: lilianabastos@yahoo.com.br

2 Professora do Programa de Pós-Graduação em Economia Doméstica da Universidade Federal de Viçosa.

E-mail: mmattos@ufv.br

\section{(). (1) (-)}

Este artigo é licenciado na modalidade acesso abertosob a Atribuição-Compartilhalgual CC BY-SA

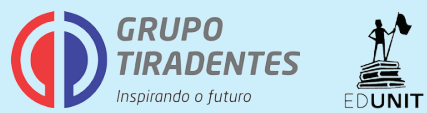


